\title{
Traffic Models Enhancements: Assessment of Eco-driving Behaviour
}

\author{
Eugenio Morello, Silvana Toffolo and Giorgio Magra \\ Department Centre for Study on Transportation Systems, IVECO S.p.A., Torino 10156, Italy
}

\begin{abstract}
The paper focuses on the enhancements needed in traffic simulation models to properly assess vehicle energy consumption and $\mathrm{CO}_{2}$ emissions when innovative ICT (information and communication technology) systems are implemented. Examples of these are the eco-driving applications. The implementations of certain ICT systems not only affect the overall traffic performance but also influence the vehicle dynamic and/or driver's attitude. This leads to different results in terms of energy consumption depending on the way in which the differences in behaviour have been modelled. The study provides analysis on the vehicle/driver behaviour which has led to some refinements of the car-following mathematical models.
\end{abstract}

Key words: Eco-driving, mathematical model, $\mathrm{CO}_{2}$ emissions.

\section{Introduction}

The eco-driving behaviour varies the attitude in setting speed and distance to the preceding vehicles. Speed and distance are parameters that influence, at the macroscopic level, the speed and density of traffic flow. Since these parameters are the basis for micro-simulation, which is used to assess impact of such way to reduce fuel consumption and in turn $\mathrm{CO}_{2}$ emissions, cares are needed to properly simulate the "standard" drivers and the "eco-drivers". Analysis on recent collected data of speed and distance profiles of "standard" and "eco" drivers has led to improvements of mathematical traffic models. In some cases, the formulations have been revised, in others, the values of the parameters have been set [1-3].

In the paper, detailed descriptions of the data analysis of the applied methodology and of the enhancements in the mathematical models are presented. The analysed measured data have been extracted from the Fiat eco-driving database, containing measured time-histories (second by second) of more than 5,000 drivers who made more than

\footnotetext{
Corresponding author: Eugenio Morello, engineer, research field: innovation for mobility. E-mail: eugenio.morello@cnhind.com.
}

400,000 trips in five months in five countries: UK, Italy, Spain, Germany and France. Detailed descriptions of the data analysis of the applied methodology and of the enhancements in the mathematical models are presented in the next sections.

\section{Car-Following Models}

Our main interest is the analysis of driver behavior and his attitude in setting speed and distance to the preceding vehicle, being these the factors which influence, from the macroscopic point of view, speed, flow and density of traffic flow and being these the factors that, for some extent, affect the "eco-behavior". Models that describe the process by which drivers follow each other in a traffic stream are generally referred to as "car following" models. During the past 50 years, driver behaviour within the traffic stream has been studied and models that attempt to describe this behaviour have been proposed, starting with simple models and then making them more and more complex in an attempt to make them more close to the actual behaviour of drivers. The main approaches undertaken are: GHR (Gazis, Herman, Rothery), General Car following model in General Motor Lab; 
safety distance or collision avoidance model $[4,5]$; psycho-physical model (action point).

To select the right model for car-following for micro-simulation, there are mainly four "keys":

- ability in matching actual data at microscopic level (speed-distance function);

- ability in matching traffic macroscopic behaviour (expressed by the fundamental diagram);

- easiness

to use

(also

with improvement/modification) to represent eco-behaviour;

- tools available used in micro-simulation.

The research has been carried out considering previous experience of people involved in the project and taking into account that three micro-simulation tools available in the project (AIMSUN, SUMO and MESSINA) are based on that "car-following" law, the selection has chosen the Gipps model $[4,5]$. Gipps model is one of the most widely studied and applied models for the microscopic simulation of traffic. It is the basis for the simulation of traffic dynamics in several micro-simulation programs. The attractiveness of the model relies on the intuitive assumption behind the formulation and on the obvious physical meaning of parameters that suggest using common practice values "without to elaborate complicated calibration procedures". Despite of these, Gipps model, as implemented in micro-simulator tool, has also some needs of improvement to satisfy the "topics" listed above. In Section 3, we will describe how we have improved Gipps model for better simulating real traffic condition and as best as possible eco-drive capabilities.

\section{Extended Gipps Model}

If we consider two vehicles traveling in the same direction in Fig. 1.

The Gipps car following model is classified as "behavioural" because it defines the law of tracking the vehicle in front, starting from the consideration that a driver tries to adapt the distance from the vehicle

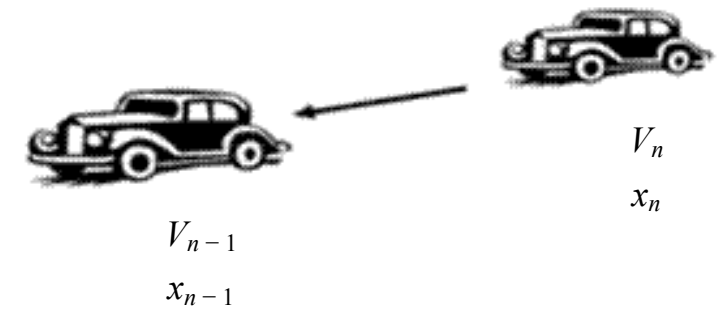

Fig. 1 Car following.

that precede as a function of speed, in order to guarantee a safe situation or, in other words, to guarantee the ability to stop before reaching the collision. The original Gipps car-following model is divided in two parts: a first law "free speed" that manages the user's behaviour at free flow, when the interactions between the vehicles are low, and a second law "following speed" that is derived from the assumption that the driver wants to keep a sort of safety distance, which manages the user's behaviour when it is engaged in following another vehicle. The "free speed" model is the following:

$$
\begin{gathered}
V_{\mathrm{lib}}(t+T)= \\
V(t)+\alpha \cdot a_{n}\left(1-V(t) / V_{d}\right)\left(\beta+V(t) / V_{d}\right)^{\gamma}
\end{gathered}
$$

where:

$T$ : delay time;

$V(t)$ : speed of vehicle at time $t$;

$V_{\text {lib }}(t+T)$ : free speed;

$a_{n}$ : max acceleration;

$V_{d}$ : max speed (the speed the driver would get if there are not constraints).

The formula generalizes those proposed by Gipps with $\alpha, \beta$ and $\gamma$ parameters to be calibrated with experimental data instead of the fix value suggested by Gipps.

The "following speed" model, based on safety distance concept, is as follow:

$$
\begin{aligned}
& V_{\text {fol }}(t+T)=b_{n} \cdot T+\left\{b_{n}^{2} \cdot T^{2}-b_{n}\left[2\left(x_{n-1}-s_{n}-x_{n}\right)-\right.\right. \\
& \left.\left.V_{n}(t) T+V_{n-1}(t)^{2} / b_{n-1}\right]\right\}^{0.5}
\end{aligned}
$$

where:

$V_{n}(t)$ and $V_{n-1}(t)$ are, respectively, the follower's and the leader's speed at time $t$;

$n$ is the follower vehicle; 
$n-1$ is the preceding vehicle;

$x_{n}, x_{n-1}$ are vehicle $n$ and $n-1$ positions;

$b_{n}$ is the most severe braking that the driver of vehicle $n$ (i.e., the follower) wishes to undertake;

$b_{n-1}$ is the follower's estimate of the leader's maximum braking rate;

$s_{n}$ is the length of vehicle $n$ plus a safety margin.

The vehicle length + safety margin $s_{n}$ and the breaking ratio $b_{n} / b_{n-1}$ have been enhanced with two sub-models able to better describe the user behaviours:

$$
\begin{gathered}
s_{n}=s_{n 0}+\gamma V^{\delta} \text { (effective length) } \\
b_{n} / b_{n-1}=\alpha_{0} \cdot\left(1-V / V_{\max }\right)^{\lambda} \text { (breaking ratio) }
\end{gathered}
$$

where, $s_{n 0}$ is the vehicle length; $V_{\max }$ is the maximal speed of the vehicle; $\gamma, \delta, \alpha_{0}, \lambda$ are parameters to be calibrated.

These two sub-models also provide us with an interesting interpretation of driver behaviour. The variability of $b_{n} / b_{n-1}$ (called $\alpha$ ) as a function of speed, with values greater than 1 at low speeds and progressively decreasing until it reaches the value 0 for the maximum speed, tells us that the "behavioral model" changes from imprudent at low speed to gradually more prudent as the speed increases, as well as the space to stop the vehicle increases as the speed increases, interpreting higher safety levels with increasing speed. The performance of the two sub-models: $s$ (effective length) and $b_{n} / b_{n-1}$ (braking ratio), are shown in Fig. 2.

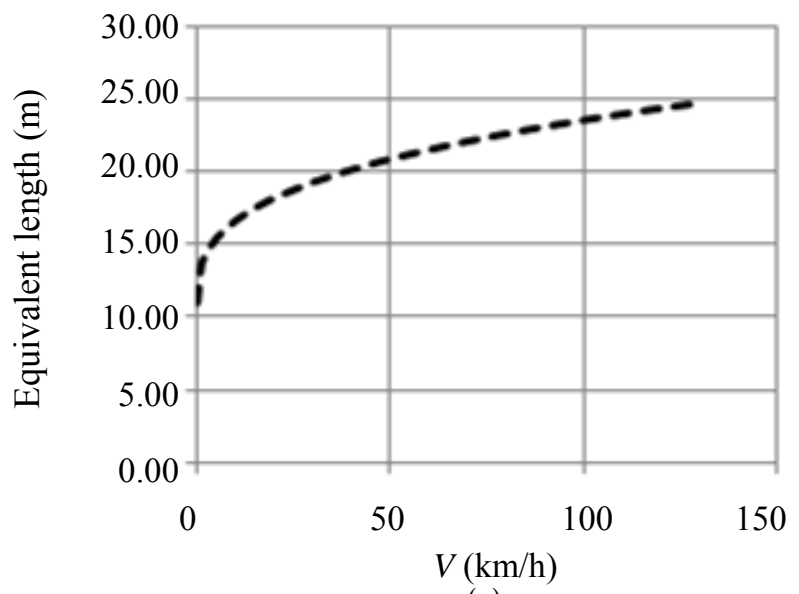

(a)

\section{The Calibration Process of the Eco-Driving Model}

The calibration process must estimate, for both categories of "normal" and "eco" driver, the optimal value for the parameters $\alpha, \beta$ and $\gamma$ for "free speed" model and parameters, $\gamma, \delta, \alpha_{0}, \lambda$, for "following speed" model. In order to define the characteristics of eco-driving behaviour, in acceleration and deceleration phase, we have analysed the journeys data of some drivers who had used the Eco-Drive system developed by Fiat.

The whole sample provided by Fiat refers to an interval of time from June 2009 until September 2009 and it is composed of about 5,000 drivers who drove about 330,000 journeys. This period does not involve months too cold and, for the analysis, this is a good thing because it allows to avoid big differences in fuel consumption due to the difference of temperatures. For the first analysis, it was decided to select from the "Eco-Drive" Database [6], no less than 100 journeys done by at least five different drivers, having the complete time-history (with a resolution second by second).

In order to define the eco-driving parameters, we should select a sample of trips which allow as to compare the same journey made by the same driver, sometime driving in "normal" way, sometime driving in "eco" way. Since it is very important to compare different behaviours ("normal" versus "eco" driving

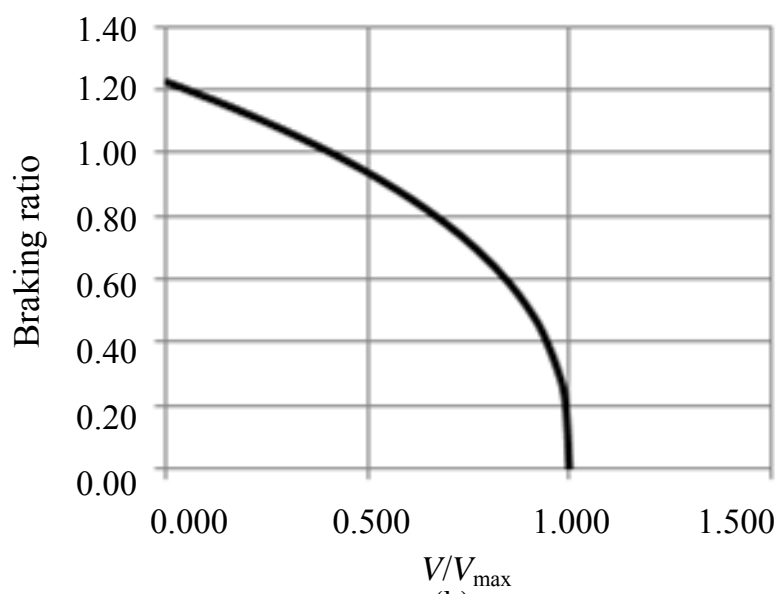

(b)

Fig. 2 Performance of the two sub-models: (a) Effective length; (b) braking ratio. 
style) of the same driver, on the same path and on the same traffic condition, we must analyse the influence of driver's behaviour on fuel consumption, independent to other parameters, like traffic, slope, etc.. In this view, the selection was done among the journeys with departure time between 5:00 a.m. and 6:00 a.m.. In that interval of time, the probability is very high that the trip is a systematic one (from home to work) and therefore it is very probable that the driver chooses the same path. Moreover, at that time, the traffic level is low and the driver has the maximum freedom to change his behavior and to drive according to his/her own style without being influenced by traffic situation.

The sample of the journeys with time of departure between 5:00 a.m. and 6:00 a.m. is composed of about 2,500 journeys $(0.8 \%$ of trips $)$ done by about 620 drivers (12.5\% of drivers). Since the Eco-Drive data do not have geo-referenced information, to identify the journeys done on the same path several times ( at least 10 times) by the same driver, we have selected, from the sample of 5:00 to 6:00 in the morning, those journeys with the same length (with a maximum difference of $100 \mathrm{~m}$ ). The condition on the length is very strict, but in this selection, we prefer to discard trips that probably are the same, rather than considering travel that looks the same but they are not. The 348 journeys done by 20 drivers satisfy these requirements. From this set, a random sample of seven drivers which made 103 journeys have been extracted.

Table 1 shows the characteristics of the vehicle used by the seven different drivers. While Table 2 shows the average characteristics of the journeys made by seven different drivers.

The overall sample accounts for 103 journeys made by seven drivers with a total of $1,231 \mathrm{~km}$ travelled in $25.3 \mathrm{~h}$. The very small value of standard deviation and CV (coefficient of variation) of journey length confirm the "repetitiveness" of the journeys made by drivers.

In Figs. 3-5, some examples of the time history (speed as a function of space travelled) of journeys performed by three different drivers are plotted.

In order to find parameters representative of the

Table 1 Vehicle characteristics by driver.

\begin{tabular}{llllll}
\hline Driver & Vehicle & Type & Displacement (cc) & Fuel & Market \\
\hline 1 & FIAT/198/N.BRAVO/I-CE & BERLINA & 1368 & Gasoline & AT \\
2 & FIAT/199/G.PUNTO/I-CE & BERLINA_5P & 1368 & Gasoline & DE \\
3 & FIAT/198/ N.BRAVO/I-CE & BERLINA & 1368 & Gasoline & DE \\
4 & FIAT/199/G.PUNTO/I-CE & BERLINA_3P & 1242 & Gasoline & DE \\
5 & FIAT/199/G.PUNTO/I-CE & BERLINA_5P & 1248 & Diesel & IT \\
6 & FIAT/312/N.CINQUECENTO/I-CE & BERLINA & 1242 & Gasoline & UK \\
7 & FIAT/198/N.BRAVO/I-CE & BERLINA & 1368 & Gasoline & DE \\
\hline
\end{tabular}

Table 2 Vehicle driver/journey characteristics.

\begin{tabular}{llllllllll}
\hline Driver $\begin{array}{l}\text { journey } \\
\text { repetition }\end{array}$ & $\begin{array}{l}\text { Average } \\
\text { length }(\mathrm{km})\end{array}$ & $\begin{array}{l}\text { Length standard } \\
\text { deviation }(\mathrm{m})\end{array}$ & CV length & $\begin{array}{l}\text { Average } \\
\text { duration } \\
(\mathrm{min})\end{array}$ & $\begin{array}{l}\text { Average speed Total } \\
(\mathrm{km} / \mathrm{h})\end{array}$ & $\begin{array}{l}\text { Total } \\
\text { duration }(\mathrm{h})\end{array}$ & Context \\
\hline 1 & 14 & 18.8 & 23.2 & $0.12 \%$ & 20.3 & 55.4 & 262.6 & 4.7 & Exurb \\
2 & 14 & 5.8 & 20.8 & $0.36 \%$ & 10.4 & 33.3 & 80.7 & 2.4 & Urb \\
3 & 12 & 34.3 & 204.8 & $0.60 \%$ & 35.6 & 57.8 & 412.0 & 7.1 & Exurb \\
4 & 14 & 17.7 & 83.3 & $0.47 \%$ & 20.9 & 50.8 & 247.2 & 4.9 & Exurb \\
5 & 11 & 8.3 & 59.3 & $0.72 \%$ & 11.4 & 43.4 & 90.9 & 2.1 & Exurb \\
6 & 18 & 3.1 & 29.2 & $0.93 \%$ & 6.5 & 29.0 & 56.6 & 2.0 & Urb \\
7 & 20 & 4.1 & 6.4 & $0.16 \%$ & 6.2 & 39.5 & 81.5 & 2.1 & Exurb \\
\hline Total & 103 & 92.0 & - & - & 111.3 & 48.7 & $1,231.5$ & 25.3 & - \\
\hline
\end{tabular}




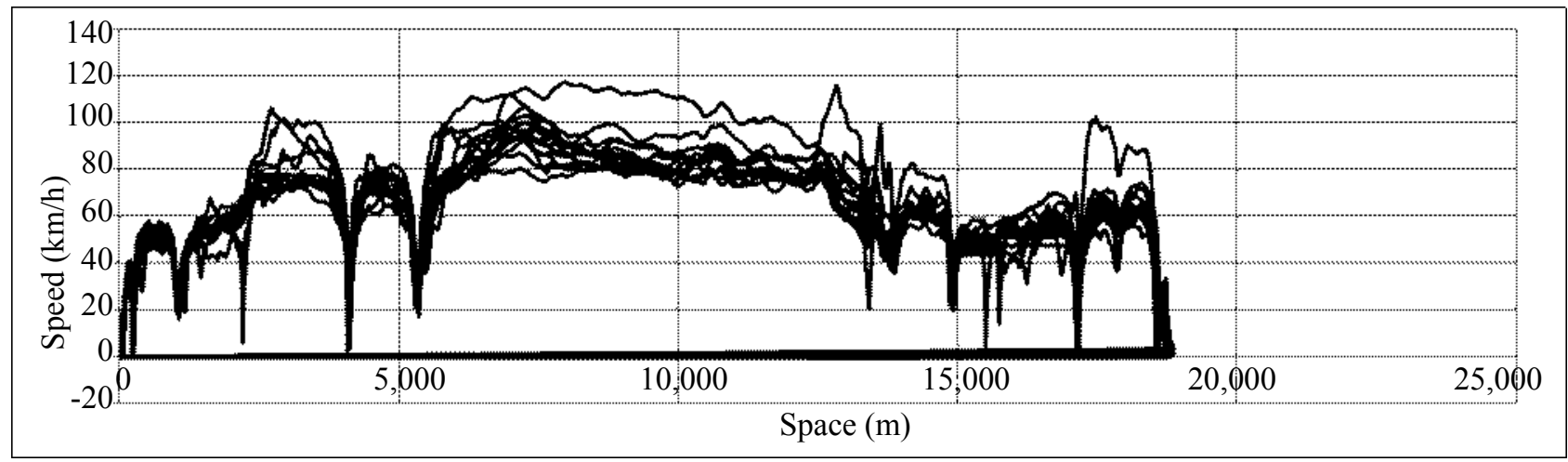

Fig. 3 Time history of Driver 1.

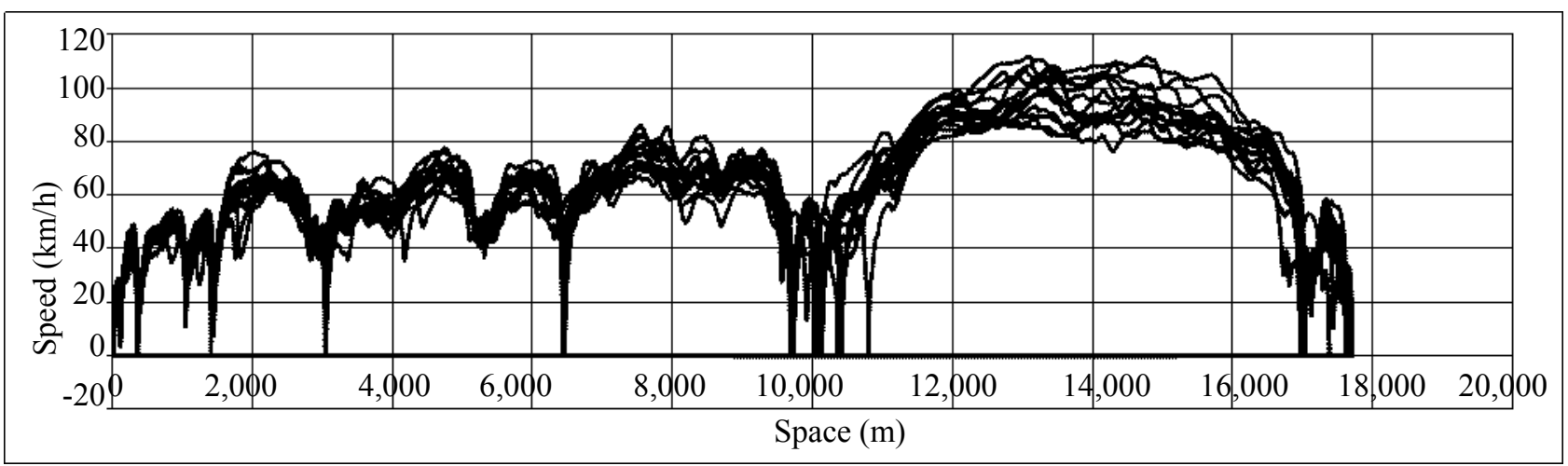

Fig. 4 Time history of Driver 4.

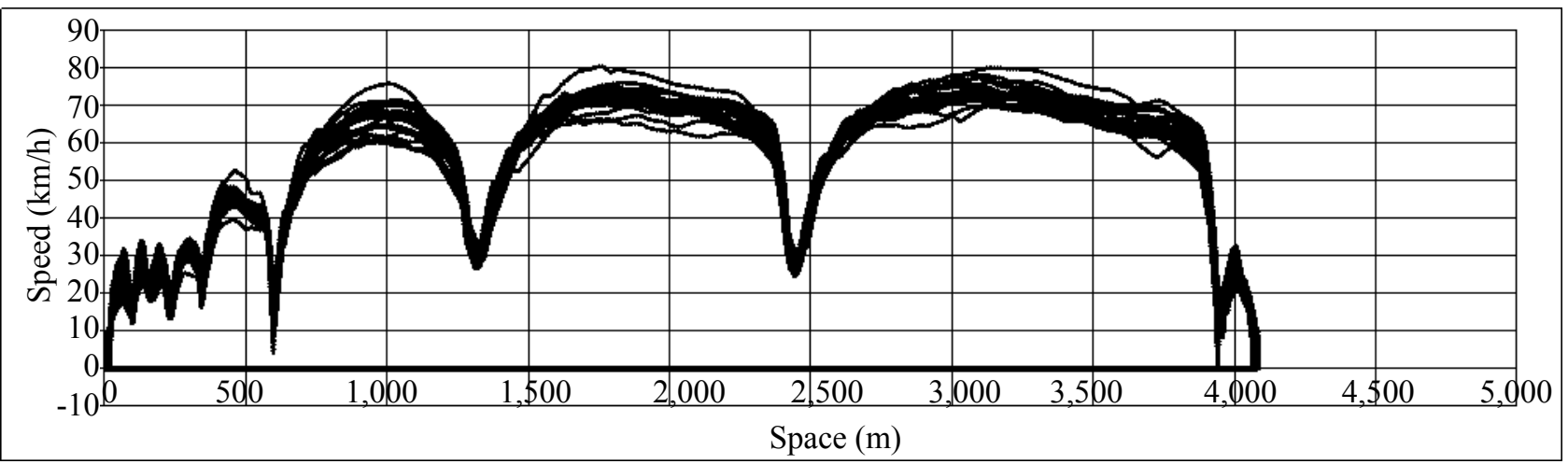

Fig. 5 Time history of Driver 7.

style of driving, a set of metrics have been computed. The metrics computed to "qualify" the trips are the following:

- average velocity $(\mathrm{km} / \mathrm{h})$;

- standard deviation of velocity $(\mathrm{km} / \mathrm{h})$;

- average of squared velocity;

- average of cubed velocity;

- average acceleration;

- inertial power;

- average of squared acceleration;
- stops per km;

- percentage of idle.

The 103 journeys extracted are classified, for the seven users, by the eco index and the mean fuel consumption measured in L/100 km (stored on Fiat "Eco-Drive" database). The relation between eco index and fuel consumption has been investigated and, even if each user has different behaviours according to the trip, it is quite evident the correlation between eco index and fuel consumptions: if your eco index is 
higher, your fuel consumption is as lower. As expected, there is also a good correlation between eco index and average acceleration.

In general, all the metrics calculated provide indication as expected. In fact, the best journey as eco index also has a good value for the stop time percentage and a high value of average duration. The velocity alone (simple, squared or cubed) among the several metrics seems, instead, the metric less related with the eco index. A criterion to select the most "eco" driven trips in order to estimate the "eco" driver model and "normal" one has been to take the journeys having the maximum value of eco index and the minimum value of fuel consumption. Hence, the analysis of the metrics tells us that the choice of taking for each user the best two trips having eco index higher and fuel consumption lower as representative of eco-drive style seems to be a good one. In the same way, the "normal" trips have been selected by the opposite criterion of taking for each user the two worst trips as eco index and fuel consumption.

\subsection{Calibration of Free Speed Model}

The aim now is to analyse the differences (if any) for the "eco" and the "normal" driver for the first sub-model (free speed). Fig. 6a shows all data belonging to the time history of "eco" journeys chosen according to the criterion explained in the previous section. Then the points of the journeys with positive acceleration has been chosen and a regression has been built estimating the relationship between acceleration and ratio between actual speed and desired one using the function suggested by Gipps (Eq. (1)). The data dispersion is very high and interpretation of average behaviour is very difficult. Then, to reduce the variability of points, the value of ratio $V / V_{d}$ has been grouped in classes having a range of 0.01 , getting a total of a hundred classes where, for each of them, the mean values, standard deviation and number of data have been computed.

Now, using average value for each class, we estimate the parameter $\alpha, \beta$ and $\gamma$ of Gipps extended model. Estimate has been done using weighted last square method (where weights are number of observation). Fig. 6b shows, using a bubbles diagram, the number of samples for each class and the standard deviation as error bars. The class with more samples is those having a low standard deviation as expected. Fig. 7 also shows the best fit for the relationship between acceleration and $V / V_{d}$ ratio.

The same methodology, of course choosing the set of trips having the opposite metrics, has been applied at journeys selected as "normal". The point has been processed in a similar way. Fig. 7 shows the distribution of these points and the free speed model for normal driver.

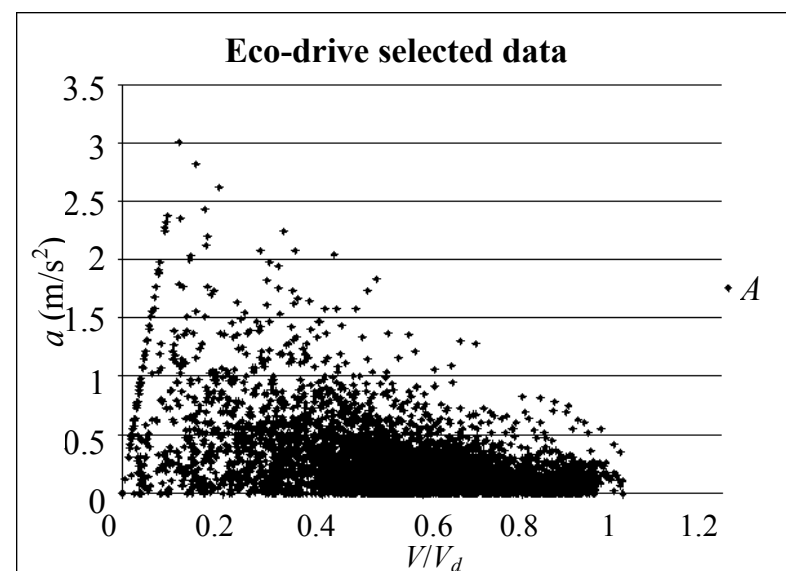

(a)

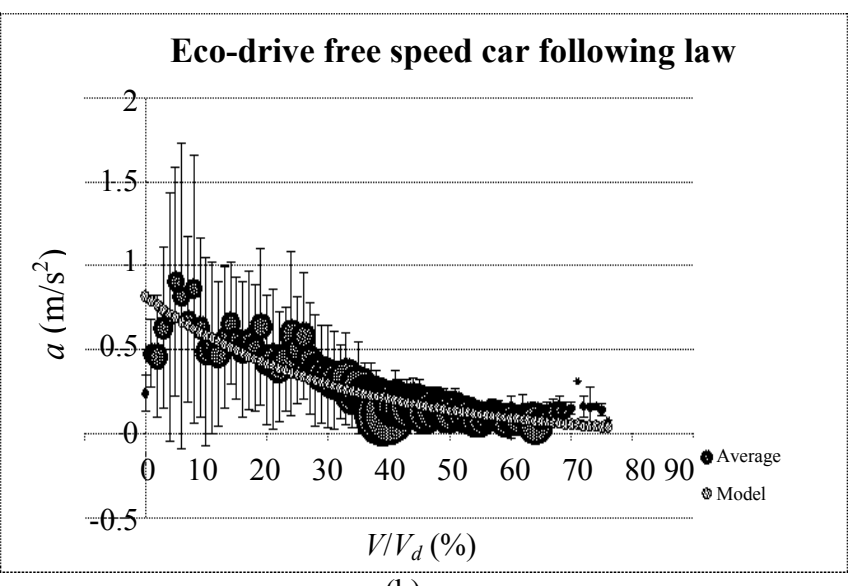

(b)

Fig. 6 Relationship between $V / V_{d}$ and acceleration for eco-driver: (a) raw points; (b) model.

The parameters of the extended Gipps model, that fit the experimental eco-drive data, are: $a_{n}=5.21,2.60,1.89,-4.42$ with a correlation coefficient $R^{2}=0.73$. 


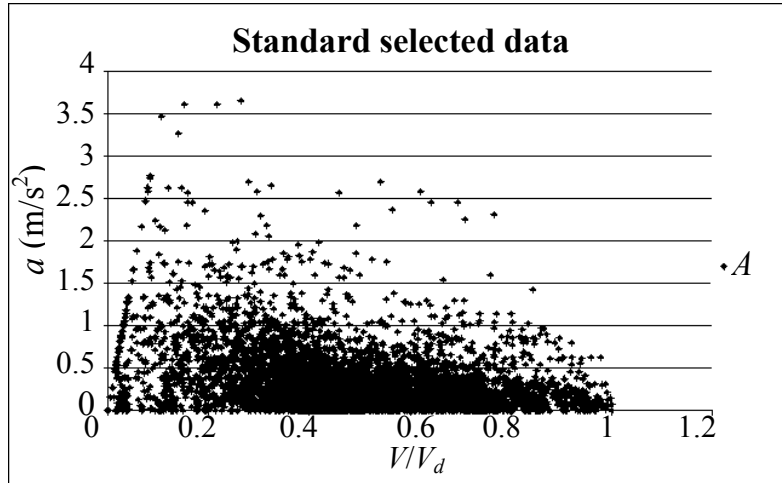

(a)

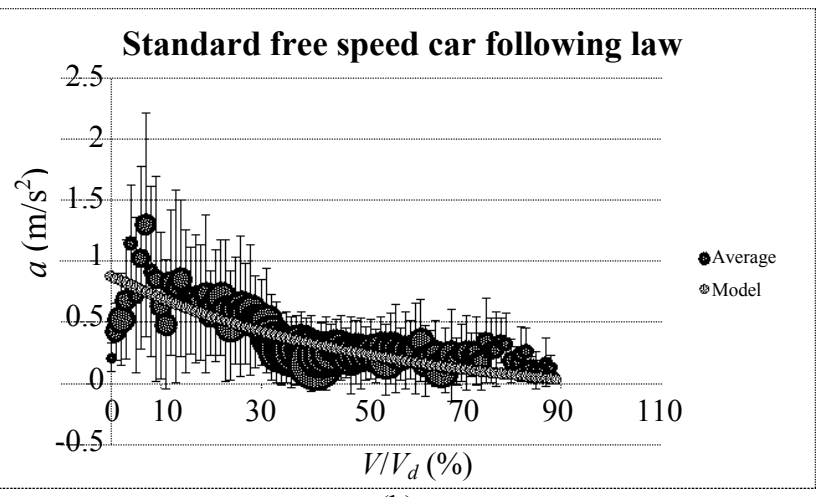

(b)

Fig. 7 Relationship between $\boldsymbol{V} / \boldsymbol{V}_{\boldsymbol{d}}$ and acceleration for normal driver: (a) raw points; (b) model.

In this "normal" case, the estimated parameters are: $a_{n}=2.95, \alpha=1.47, \beta=1.91, \gamma=-2.47$ with a correlation coefficient $R^{2}=0.62$.

Eco-drive vs. no eco-drive law

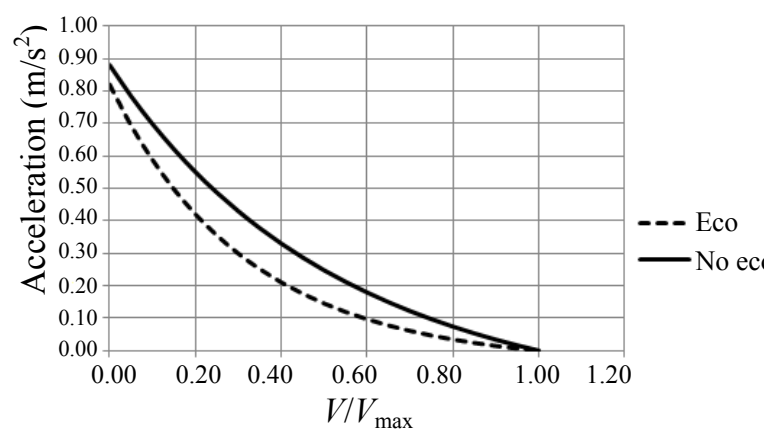

(a)
Eco-drive vs. no eco-drive law

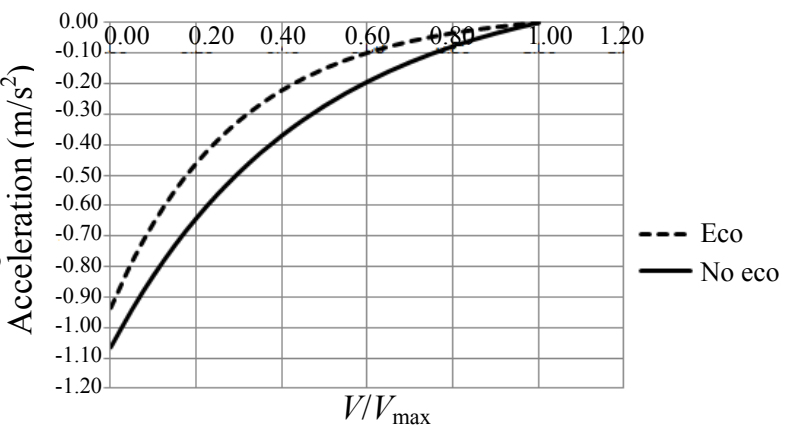

(b)

Fig. 8 (a) Acceleration and (b) deceleration function for eco-drive and "normal" driver.

Fig. 8a, finally, shows the comparison between the two estimated curve for "eco" and "normal" driver. The eco-driver curve is always below the "normal, no eco" driver curve. This means that eco-drive behaviour tends to reduce the acceleration, as expected.

Using the same method applied for analysing the acceleration described above, we also obtain the relations for deceleration as function of the $V / V_{d}$ ratio (Fig. 8b).

Also in this case, eco-driving deceleration is lower than those for normal driver.

\subsection{Calibration of Following Speed Model}

The data from Fiat "Eco-Drive" database rely on behaviour of "single" vehicle. There are not any data concerning the distance and speed of the car in the front. This means that there is no possibility to use these data to estimate parameter of the "following speed" model which requires, by definition, data of follower and leading vehicle, so we have to follow another approach.

Since we know that micro behaviour (speed-distance law) must be coherent with traffic macro behaviour (fundamental diagram) [7], we can use this relation to estimate, at least for the normal driver, the distance-speed law and, in turn, the car following model. To do that, we have estimated the FD (fundamental diagram) for the "average lane" of a road section belonging to a two lane motorway. For the estimate, we have used the FD formulation proposed by Cremer:

$$
v=v_{f f}\left[1-\left(k / k_{j}\right)^{\alpha}\right]^{\beta}
$$

where:

$v_{f f}$ free flow speed;

$k$ : density;

$k_{j}$ : jam density;

$\alpha, \beta$ : parameters to be calibrated.

The typical parameters for the traffic on two-lane highway are: $v_{f f}=123 \mathrm{~km} / \mathrm{h} ; k_{j}=91 \mathrm{Veic} / \mathrm{km} ; \alpha=1.4$; 
$\beta=4$.

In Figs. 9 and 10, the shape of the fundamental diagram and those built integrating the original Gipps speed-distance model (with a braking ratio $=0.75$ ) are reported together.

If we use the "enhanced model" [6] (with effective length [5] and braking ratio [7] sub models) for speed-distance law, a decisive improvement in the validity of the model is obtained. Fig. 10 shows the comparison between this new model and the FD. The improvement is well evident.

The parameters were determined using least squares technique:

$$
\begin{gathered}
\tau=1 \mathrm{~s}, \lambda=0.3862 \\
b=4 \mathrm{~m} / \mathrm{s}^{2}, s_{0}=11 \mathrm{~m} \\
V_{\max }=123 \mathrm{~km} / \mathrm{h}, \gamma=2.561 \\
\alpha_{0}=1.224, \delta=0.3446
\end{gathered}
$$

As a measure of the goodness of the fit, we use the value of correlation coefficient $R^{2}$ of the regression between the values calculated with the speed-distance model and those calculated with the fundamental diagram law. The value of $R^{2}$ is equal to 0.999 with the following regression equation:

$$
\text { Flow_CF }=1.0021 \text { flow_DF }
$$

As said before, this can be considered adequate for the "normal" driver. Unfortunately, we have no any data collected on board of vehicle to see how the behavior of eco-driver affects the shape of the speed-distance law.

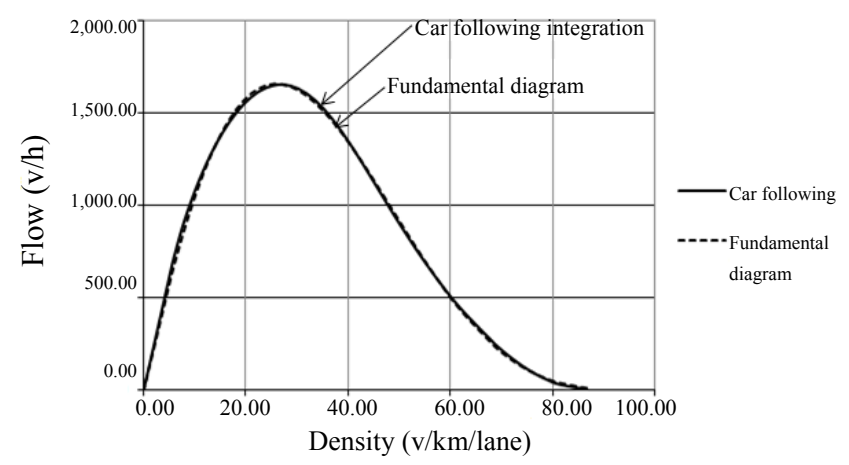

(a)

\section{Results and Discussions}

To check the correctness and realism of the model's enhancement (Section 4) and the effect of eco-driving behaviour, we have used the speed profile of the seven selected trips (Section 4), as speed profile of a "leader vehicle", while the behaviour of the follower vehicle has been simulated using the enhanced Gipps model, considering two scenarios: the first "normal", adopting acceleration and deceleration functions for "normal driver" (Section 4.1) and the second "eco", adopting acceleration deceleration function for "eco-driver" (Section 4.1). Comparison has been made in terms of fuel consumption. Within the simulation tool, we have implemented the Akcelic fuel consumption model (one of the most used in microsimulation tool). The model consider the behaviour in each phase of driving task (acceleration, deceleration, cruising and idle), according to these rules:

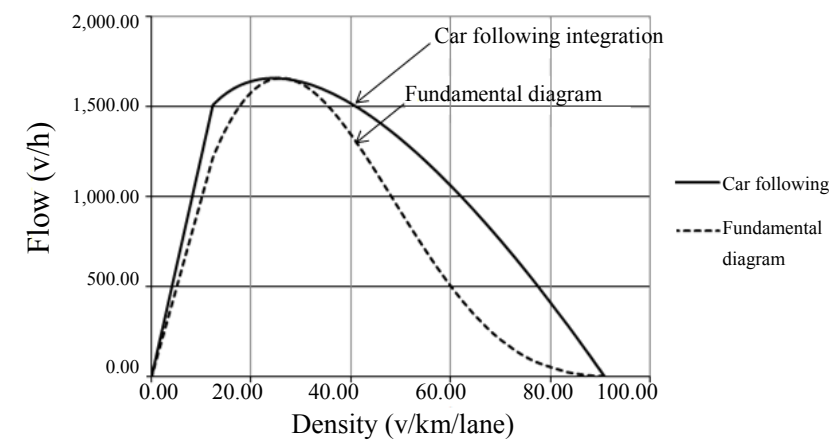

Fig. 9 Fundamental diagram (density-flow function).

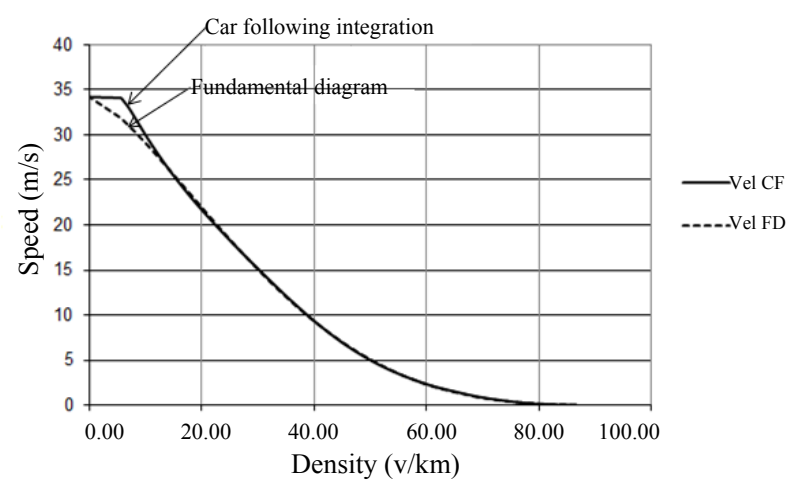

(b)

Fig. 10 (a) FD density-flow functions; (b) FD density-speed functions. 
Table 3 Akcelic fuel consumption model.

\begin{tabular}{ll}
\hline Vehicle state & Fuel consumed $(\mathrm{mL})$ during $\Delta t$ \\
\hline Idling & $F_{i} \Delta t$ \\
Accelerating with acceleration $a\left(\mathrm{~m} / \mathrm{s}^{2}\right)$ and speed $v(\mathrm{~m} / \mathrm{s})$ & $\left(c_{1}+c_{2} a v\right) \Delta t$ \\
Cruising speed $v(\mathrm{~m} / \mathrm{s})$ & $\left(k_{1}\left(1+\left(v / v_{m}\right)^{3}\right)+k_{2} \Delta v\right) \Delta t$ \\
Decelerating & $F_{d} \Delta t$ \\
\hline
\end{tabular}

$F_{i}$ and $F_{d}$ are the constant fuel consumption rate in $\mathrm{mL} / \mathrm{s}$ for idling and deceleration phases; $c_{1}$ and $c_{2}$ are parameters to be calibrated (depending on vehicle model); $k_{1}$ and $k_{2}$ are parameters to be computed knowing true fuel consumption for $90 \mathrm{~km} / \mathrm{h}$ and $120 \mathrm{~km} / \mathrm{h} ; v_{m}$ is the speed at which the fuel consumption rate is at minimum for a vehicle cruising at constant speed.

Table 4 Characteristics of driving phases $(\mathrm{Vel}=$ speed and $F \mathrm{C}=$ fuel consumption $)$.

\begin{tabular}{|c|c|c|c|c|c|c|}
\hline & \multicolumn{2}{|c|}{$\operatorname{Vel}(\mathrm{km} / \mathrm{h})$} & \multicolumn{2}{|c|}{$F C(\mathrm{~L} / 100 \mathrm{~km})$} & \multicolumn{2}{|c|}{ Delta\% (eco vs. no eco) } \\
\hline & Eco & No eco & Eco & No eco & $\mathrm{Vel}$ & $F C$ \\
\hline Cruise & 58.8 & 62.9 & 5.5 & 5.8 & $-6.5 \%$ & $-4.6 \%$ \\
\hline Acceleration & 44.7 & 50.8 & 9.5 & 11.4 & $-12.1 \%$ & $-16.7 \%$ \\
\hline Deceleration & 42.7 & 49.9 & 2.7 & 2.5 & $-14.5 \%$ & $8.3 \%$ \\
\hline Idle & 0.0 & 0.0 & 0.0 & 0.0 & - & - \\
\hline Total & 48.8 & 49.0 & 6.0 & 6.8 & $-0.5 \%$ & $-12.0 \%$ \\
\hline
\end{tabular}

Table 5 Characteristics of driving phases (share of phases in terms of $T T=$ travel time, space travelled and $F C=$ fuel consumption).

\begin{tabular}{|c|c|c|c|c|c|c|}
\hline & \multicolumn{2}{|c|}{$T T$} & \multicolumn{2}{|c|}{ Space } & \multicolumn{2}{|c|}{$F C$} \\
\hline & Eco & No eco & Eco & No eco & Eco & No eco \\
\hline Cruise & $52.4 \%$ & $36.2 \%$ & $63.1 \%$ & $46.4 \%$ & $57.9 \%$ & $39.3 \%$ \\
\hline Acceleration & $22.1 \%$ & $27.9 \%$ & $20.2 \%$ & $28.9 \%$ & $31.8 \%$ & $48.0 \%$ \\
\hline Deceleration & $19.1 \%$ & $24.2 \%$ & $16.7 \%$ & $24.6 \%$ & $7.4 \%$ & $8.9 \%$ \\
\hline Idle & $6.5 \%$ & $11.6 \%$ & $0.0 \%$ & $0.0 \%$ & $2.9 \%$ & $3.8 \%$ \\
\hline Total & $100 \%$ & $100 \%$ & $100 \%$ & $100 \%$ & $100 \%$ & $100 \%$ \\
\hline
\end{tabular}

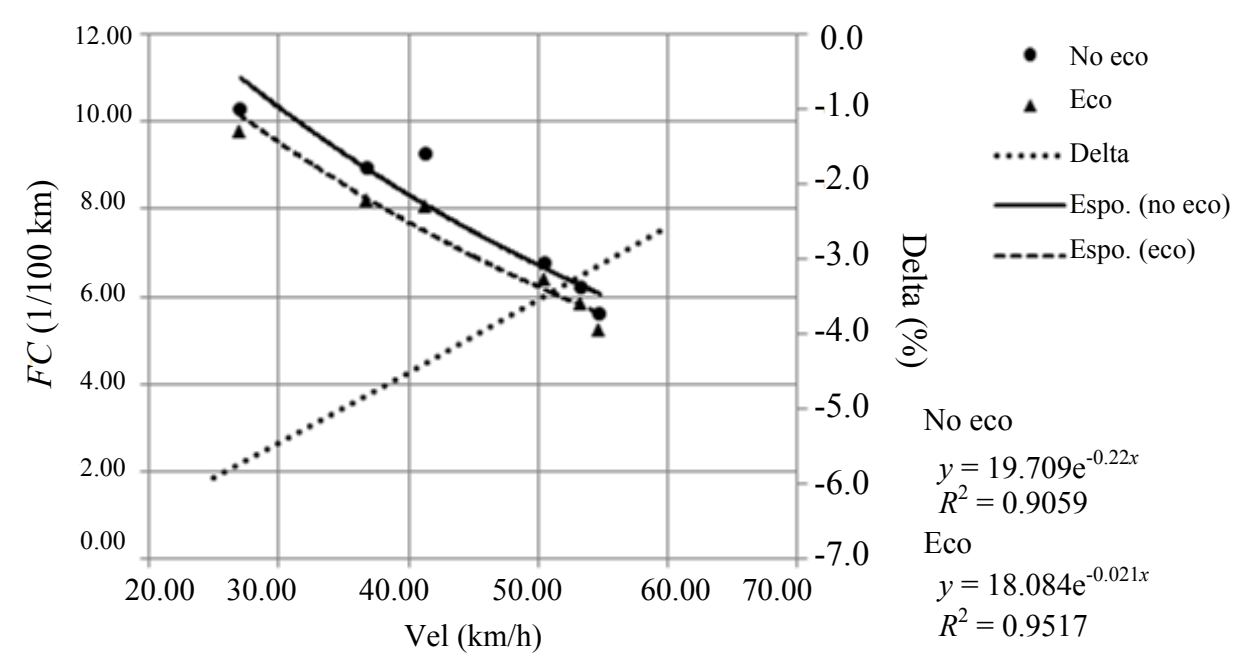

Fig. 11 Speed-FC functions (Espo. means exponential curve and delta means FC difference between eco and noeco in \%).

- idle if $V<0.1 \mathrm{~m} / \mathrm{s}$ and $|a|<0.15 \mathrm{~m} / \mathrm{s}^{2}$;

- acceleration if $a>0$;

- cruise if $V>0.1 \mathrm{~m} / \mathrm{s}$ and $|a|<0.15 \mathrm{~m} / \mathrm{s}^{2}$;

- deceleration if $a<0$.

In Table 3, the Akcelic fuel consumption model for each phase is presented.
Each phase, on the set of trips extracted from the "Eco-Drive" Database, has been analysed. In Tables 4 and 5 , results of main characteristics of different phases and share of them (on travel time, on distance travelled and fuel consumption) are reported.

The eco-driving effect on reduction of fuel 
consumption is mainly due to different behaviour in acceleration (Table 5). From field data, the average fuel consumption reduction is around $12 \%$, while the reduction of fuel consumption in the acceleration phase is around $17 \%$. Applying simulation (with the extended Gipps model and acceleration function as described in Section 4.1), we have an average fuel consumption reduction around $8 \%$ with a reduction on acceleration phase around $16 \%$. This confirms a quite good match of simulated data with those coming from the field.

It is also interesting to note that if, instead of considering just the average consumption for each trip, we link these to the average speed for the overall trip, we can estimate the relationship between speed and fuel consumption. Fig. 11 shows the results.

As expected, fuel consumption is a decreasing function of the average trip speed and fuel consumption with eco-driving behaviour is lower than with normal behaviour.

Fuel consumption percentage reduction is almost linearly decreasing with the speed, considering average speed of selected trips, fuel consumption reduction is around $4.5 \%$.

\section{Conclusions}

Enhancement of Gipps car following model with introduction of specific submodels for "vehicle equivalent length" and "braking ratio", and new calibration of "free speed" model with actual data coming from vehicle used in real life, allowed to estimate effect of eco-driving behavior on reduction of fuel consumption.

Quantitative results are quite good: average reduction of fuel consumption for the sample of actual trips is around $12 \%$. Average reduction for the same speed profile used within the simulation tool is around $8 \%$, while considering a more conservative evaluation which takes into account relationship between average trip speed and fuel consumption. Final estimate of fuel consumption reduction is around $4.5 \%$ which is a value very close to the usual target for this measure.

\section{References}

[1] Horiguchi, R. 2010. "Validation Scheme for Traffic Simulation to Estimate Environmental Impacts in 'Energy-ITS Project'." Accessed March 1, 2014. http://www.i-transportlab.jp/publications/papers/pdf/ITSW C2010Busan_E-ITS_20100731.pdf.

[2] Morello, E. 2013. "Methodology-Annex 2: Car Following Model Change First Analysis of Ecodrive Data." ICT-Emissions (Development of a Methodology and Tool to Evaluate the Impact of ICT Measures on Road Transport Emissions) Project-FP7-ICT-2011-7, Deliverable 2.1. Annex 2.

[3] Taniguchi, M. 2007. "A Study on the Effect of Eco-driving Trainings to Fuel Consumption." SAE paper 2007-08-0632.

[4] Biagio, C., Punzo, V., and Montanino, M. 2012. “30 Years of the Gipps' Car-Following Model: Applications, Developments and New Features." Presented at PTRB 2012 Annual Meeting, Washington, DC.

[5] Gipps, P. G. 1981. “A Behavioural Car-Following Model for Computer Simulation." Transportation Research Board Part B 15 (2): 105-11.

[6] Fiat Eco-drive. 2010. "Eco-driving Uncovered-The Benefit and Challenges of Eco-driving, Based on the First Study Using Real Journey Data." Fiat Eco-drive. Accessed March 1, 2014. http://www2.fiat.co.uk/ ecodrive/\#ecodrive/intro.

[7] Transportation Research Board. 2000. Highway Capacity Manual. Washington DC: National Research Council. 